\title{
Responses of immature dental pulp cells to hypoxic stimulation
}

\author{
Sachie Senzui ${ }^{1,2}$, Kenichi Matsuzaka ${ }^{1,3}$, Fumiko Fukuhara ${ }^{1,2}$, Seikou Shintani ${ }^{1,2}$, Takashi Inoue ${ }^{1,3}$ \\ ${ }^{\prime}$ Oral Health Science Center hrc7, Tokyo Dental College, Chiba, Japan \\ ${ }^{2}$ Department of Pediatric Dentistry, Tokyo Dental College, Chiba, Japan \\ ${ }^{3}$ Department of Clinical Pathophysiology, Tokyo Dental College, Chiba, Japan
}

Abstract: The purpose of this study was to evaluate the responses of immature young pulp cells under conditions of hypoxia with or without reoxygenation. Proliferative activity and bone related protein mRNAs were evaluated. Proliferation ratios in the hypoxia only and hypoxia with reoxygenation groups were significantly lower than those in the control group on days 2 and 3. On day 4 , there was no significant difference between the control and the reoxygenation group. There was no significant difference in alkaline phosphatase (ALP) mRNA among the control, hypoxia and reoxygenation groups at any of the time periods. Expression of dentinsialophosphoprotein (DSPP) mRNA was significantly lower in the hypoxia group than in the control and the reoxygenation group on days 2 and 3 . Hypoxic condition suppressed the expression of a gene specific to odontoblasts in immature young pulp cells, suggesting that it affects the differentiation ability of odontoblasts.

[Oral Med Pathol 2010; 14: 107-111 doi: 10.3353/omp.14.107]

Key words: ALP, dental pulp cells, DSPP, HIF-1 $\alpha$, VEGF, RT-PCR

Correspondence: Kenichi Matsuzaka, Clinical Pathophysiology, Tokyo Dental College, 1-2-2 Masago, Mihama-ku, Chiba 261-8502, Japan

Phone: +81-43-270-3582, Fax: +81-43-270-3583, E-mail: matsuzak@tdc.ac.jp

\section{Introduction}

Hypoxic conditions of intraoral tissue occur for various reasons, including orthodontic tooth movement, use of local anesthesia containing vasoconstrictors, and occlusal trauma. During orthodontic tooth movement, the periodontal ligament is exposed either to pressure or to an attractive effect causing hypoxic conditions of the tissues (1). Administration of local anesthesia containing a vasoconstrictor reduces peripheral blood flow and causes hypoxic conditions in the pulp and in the periodontal ligament $(2,3)$. Occlusal trauma results in peripheral circulatory disturbances and vascularization (4). Research has shown that blood flow decreases to less than $40 \%$ of normal in the brain, aerobic metabolism stops and irreversible tissue damage ensues because of energy failure $(5,6)$. There are many reports related to oral cell responses under conditions of either hypoxia or hypoxia with reoxygenation. Such conditions may stimulate periodontal ligament cells to produce bone resorbing factors, which result in the progression of alveolar bone resorption (7), although periodontal ligament cells maintain homeostasis during hypoxia and reoxygenation (8). Moreover, pulp cells are also known to exhibit hypoxiaresistance and to enhance their physiological functions (9-11). In particular, the proliferation of pulp cells progresses in a low-oxygen environment because hypoxia increases mitochondrial function and the proliferative activity of the pulp (9). On the other hand, it is generally considered that immature young pulp tissue is functionally different from aged pulp tissue. However, little is known about the responses of immature young pulp cells to hypoxic conditions in vivo and in vitro.

In this study, we evaluated the responses of immature young pulp cells of rats under conditions of hypoxia with or without reoxygenation. Amemiya et al. (9) suggested that vascular endothelial growth factor (VEGF), which is an angiogenic growth factor that elicits cellular responses to hypoxia (12), increases alkaline phosphatase (ALP) activity under conditions of hypoxia. For those analyses, proliferative activity and reverse transcriptase polymerase chain reaction (RT-PCR) assays were performed to examine the effects of VEGF, hypoxia inducible factor- $1 \alpha$ (HIF-1 $\alpha$ ), alkaline phosphatase, and dentin sialophosphoprotein (DSPP).

\section{Materials and methods}

This study was conducted in compliance with the guidelines for the treatment of experimental animals at the Tokyo Dental College. Five male 14-day-old SpragueDawley rats, weighing approximately 50 g each (Sankyo Labo Service, Tokyo, Japan) were used for these studies because their molars show immature conditions, with crown formation but without any roots. 


\section{Histological observation}

Each rat was sacrificed with an overdose of thiopental (Ravonal; Tanabe, Osaka, Japan). The mandible and maxilla were removed and fixed in neutral-buffered formalin (10\%) for 3 days, and then were decalcified in formic acid for 1 week before being embedded in paraffin. Paraffin sections were cut in the sagittal plane, and sections were stained by hematoxylin and eosin.

\section{Cell culture}

Rats were sacrificed as noted above and the oral mucosa was sterilized with $70 \%$ ethanol. The first and second molars of both jaws were extracted mechanically. The teeth were immediately placed in alpha-minimal essential medium ( $\alpha$-MEM; Gibco, Carlsbad, CA, USA) containing $500 \mu \mathrm{g} / \mathrm{ml}$ gentamicin (Sigma Chemical Co., St. Louis, MO, USA), and $0.3 \mu \mathrm{g} / \mathrm{ml}$ fungizone (Gibco). The pulp tissue was carefully removed from the pulp chamber with a dental explorer. Thereafter, the removed pulp tissue was treated according to the method of Zhang et al. (13). Briefly, the pulp tissue was minced and digested with $3 \mathrm{mg} / \mathrm{ml}$ collagenase type I for 1 $\mathrm{hr}$ at $37^{\circ} \mathrm{C}$ with gentle shaking. Cell suspensions were obtained by passing the digested tissue through a $70 \mu \mathrm{m}$ cell strainer. Single cell suspensions were seeded in $\operatorname{Coster}^{\circledR} 24$ well microplates (Corning Inc., Corning, NY, USA) and incubated under a humidified atmosphere of $95 \%$ air and $5 \%$ $\mathrm{CO}_{2}$ at a temperature of $37^{\circ} \mathrm{C}$, in $\alpha$-MEM culture medium containing $10 \%$ fetal bovine serum (inactivated at $56^{\circ} \mathrm{C}$ for $35 \mathrm{~min}$, Gibco), $40 \mu \mathrm{g} / \mathrm{ml}$ gentamicin and $10 \mu \mathrm{g} / \mathrm{ml}$ fungizone. The culture medium was changed every $48 \mathrm{hrs}$. When the pulp cells reached confluence, they were detached using $0.1 \%$ trypsin $/ 0.02 \%$ ethylenediamine tetraacetic acid (EDTA) (pH 7.2) at $37^{\circ} \mathrm{C}$ for 1 min to subculture. Cells from the fifth subculture were used in the following experiments.

\section{Hypoxia and reoxygenation conditions}

Hypoxia and reoxygenation conditions were set according to the method of Amemiya et al (9). For the control group, cells were incubated under a humidified atmosphere at normoxic conditions $\left(20 \% \mathrm{O}_{2}, 5 \% \mathrm{CO}_{2}\right.$, and $75 \% \mathrm{~N}_{2}$ at $37^{\circ} \mathrm{C}$ ) for 1 to 4 days. For the hypoxia group, cells were incubated under a humidified atmosphere of $2 \% \mathrm{O}_{2}$, $5 \% \mathrm{CO}_{2}$, and $93 \% \mathrm{~N}_{2}$ at $37^{\circ} \mathrm{C}$ for 1 to 4 days. For the reoxygenation group, cells were first incubated under the same conditions as the hypoxia group for $24 \mathrm{hrs}$ and then were changed to the normoxic conditions and cultured for 1 to 3 additional days. The medium was not changed during the experimental period in all groups.

\section{Proliferation assay}

Approximately $3 \times 10^{4}$ cultured cells were seeded in 35-mm cell-dishes (Corning) and were incubated for 1 to 4 days at each of the culture conditions described above. Cells were detached using $0.1 \%$ trypsin/0.02\% EDTA (pH 7.2) at each time-point, and the numbers of detached cells were counted a Coulter Counter (Beckman Coulter, Inc., Fullerton, CA, USA).
Quantitative reverse transcription-polymerase chain reaction (RT-PCR)

Approximately $3 \times 10^{4}$ dental pulp cells were seeded in $35 \mathrm{~mm}$ dishes and were cultured as detailed above. Total RNA was extracted from each sample using the acid guanidium thiocyanate/phenol-chloroform method as follows. The culture medium was removed, and cells were then rinsed twice using phosphate-buffered saline. The cells were homogenized in $1 \mathrm{ml}$ TRIsol ${ }^{\circledR}$ reagent (Invitrogen) after 1, 2, 3 and 4 days of incubation. Each solution was transferred to a $1.5 \mathrm{ml}$ tube containing chloroform and mixed. The tubes were centrifuged at $13,200 \mathrm{rpm}$ at $4^{\circ} \mathrm{C}$ for $20 \mathrm{~min}$, after which the supernatants were placed in $1.5 \mathrm{ml}$ tubes containing $250 \mu 100 \%$ isopropanol (half the amount of the TRIsol reagent) at $-80^{\circ} \mathrm{C}$ for $1 \mathrm{hr}$. After centrifugation at $13200 \mathrm{rpm}$ at $4^{\circ} \mathrm{C}$ for $20 \mathrm{~min}$, the supernatants were discarded and the remaining total RNA pellets were washed with $70 \%$ cold ethanol. Total RNAs were dissolved in $50 \mu \mathrm{l}$ RNAase-free (diethylpyrocarbonate treated) water and then were reverse transcribed and amplified in $20 \mu \mathrm{l}$ volumes using a reverse transcription kit (Quanti Tect; Qiagen, Germantown, MD, USA) containing RNA polymerase chain reaction (PCR) buffer $(2 \mathrm{U} / \mu \mathrm{l}$ RNAase inhibitor, $0.25 \mathrm{U} / \mu \mathrm{l}$ reverse transcriptase, $0.125 \mu \mathrm{M}$ oligo dt-adaptor primer, 5 $\mathrm{mM} \mathrm{MgCl} 2$ in RNAase-free water). RT-PCR products were analyzed by quantitative real-time RT-PCR in TaqMan Gene Expression Assays (Applied Biosystems, Inc., Foster, CA, USA) for the target genes: HIF-1 $\alpha$ (Rn00577560_m1, 72 bp), VEGF (Rn00582935_m1, 75 bp), ALP (Rn01516028_ m1, 68 bp), DSPP (Rn02132391_s1, 87 bp). The TaqMan Endogenous Control (Applied Biosystems) for the target gene $\beta$-actin (Rn01768120_m1, 63 bp) was used as an endogenous control. All PCR reactions were performed using a real-time PCR 7500 fast system (Applied Biosystems). Gene expression quantitation using TaqMan Gene Expression Assays was performed as the second step in a two-step RTPCR. Assays were done in 20- $\mu$ l single-plex reactions containing TaqMan Fast Universal PCR Master Mix, TaqMan Gene Expression Assays, distilled water and

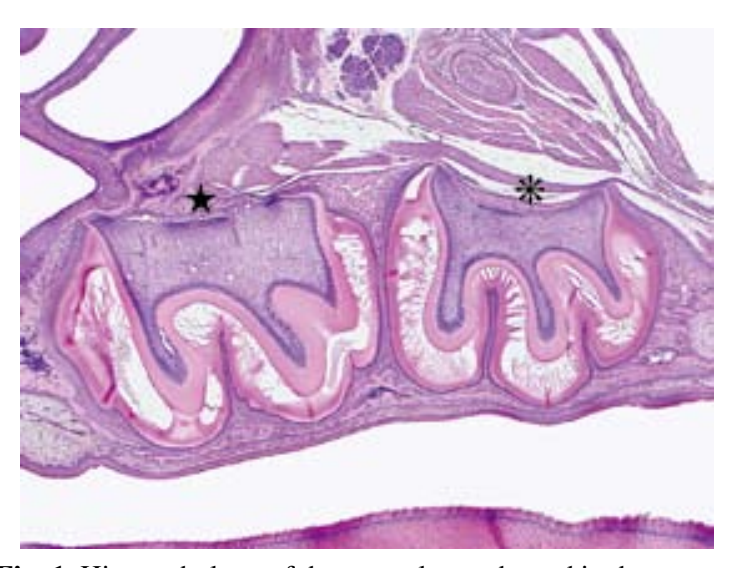

Fig. 1. Histopathology of the rat molar teeth used in the present study. Hematoxylin and eosin stain, $\times 15$. First molar tooth $(*)$; and the second molar tooth $(\star)$ of the maxilla. The first and second molars of both jaws were unerupted and were covered by connective tissue with an oral squamous epithelium. 


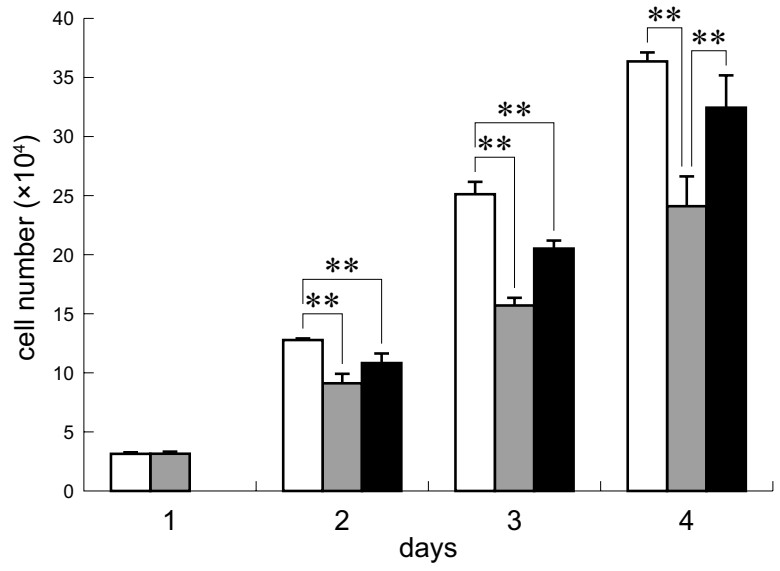

Fig. 2. Cell proliferation assay of rat immature dental pulp cells in culture. $\square$, Control; $\square$, hypoxia; $\square$, reoxygenation. Proliferation ratios in the hypoxia and re-oxygenation groups were significantly lower than those in the control group on days 2 and $3(* * P<0.01)$. On day 4 , there was no significant difference between the control and the reoxygenation groups.

complementary DNA, according to the manufacturer's instructions (Applied Biosystems). Reaction conditions consisted of 40 cycles at $95^{\circ} \mathrm{C}$ for $3 \mathrm{sec}$ and at $62^{\circ} \mathrm{C}$ for 30 sec.

\section{Statistical analysis}

Five experimental runs were conducted and data were analyzed using the ANOVA one-way analysis of variance and a multiple-comparison test (Scheffe's test, MS Excel 2003 add-in). Data are expressed as means \pm standard deviation (SD) with the control group $(\mathrm{n}=5)$. Differences at $P<0.05$ were considered to be statistically significant.

\section{Results}

\section{Histological findings}

The first and second molars of both jaws were unerupted and were covered by connective tissue with an oral squamous epithelium (Fig. 1). However, the crown formation of the first molar was already complete and elongation of Hertwig's root sheath was observed. The crown formation of the second molar was incomplete.

\section{Proliferation ratios}

The proliferation ratios increased in all groups in a time-dependent manner (Fig. 2). It was significantly lower in the hypoxia group than in the control group on days 2,3 and $4(P<0.01)$. The proliferation ratio in the reoxygenation group was significantly lower than that in the control group on days 2 and $3(P<0.01)$. However, the ratio in the reoxygenation group recovered to a level similar to that of the control group on day 4 although it was significantly lower on days 2 and $3(P<0.01)$.

\section{mRNA expression levels}

The expression of HIF- $1 \alpha$ mRNA in the hypoxia group was higher than that in the control group on days $2(P<0.05)$, 3 , and $4(P<0.01)$ (Fig. 3). It was also higher in the

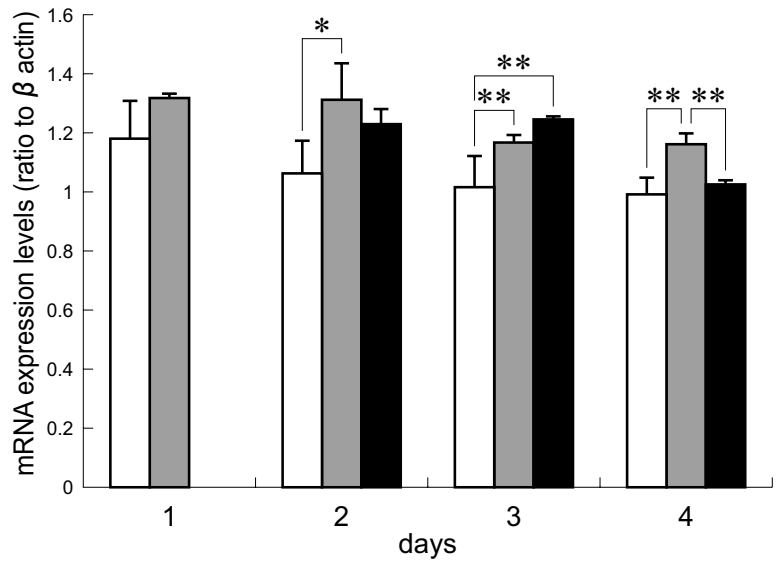

Fig. 3. mRNA expression levels of hypoxia inducible factor $1 \alpha$ (HIF-1 $\alpha)$ in hypoxic conditions of rat dental pulp cells in culture. $\square$, Control; $\square$, hypoxia; $\square$, reoxygenation. Expression of HIF-1 alpha mRNA increased at days 2 $(* P<0.05), 3$ and $4(* * P<0.01)$ in the hypoxia group compared with the control group. Expression of HIF-1 $\alpha$ mRNA increased at day 3 in the reoxygenation group compared with the control group $(P<0.01)$. There was no significant difference in HIF-1 $\alpha$ mRNA between the control and the reoxygenation group at day 4 .

reoxygenation group than in the control group on day 3 $(P<0.01)$. The expression in the reoxygenation group was lower than that in the hypoxia group on day $4(P<0.01)$.

The expression of VEGF mRNA in the reoxygenation group was significantly higher than in the control and the hypoxia groups on day $3(P<0.01)$ (Fig. 4). There was no significant difference in VEGF mRNA among the control, the hypoxia and the reoxygenation groups on days 1,2 , and 4.

The expression of ALP mRNA in both the hypoxia and reoxygenation groups was similar to that in the control group at each time point.

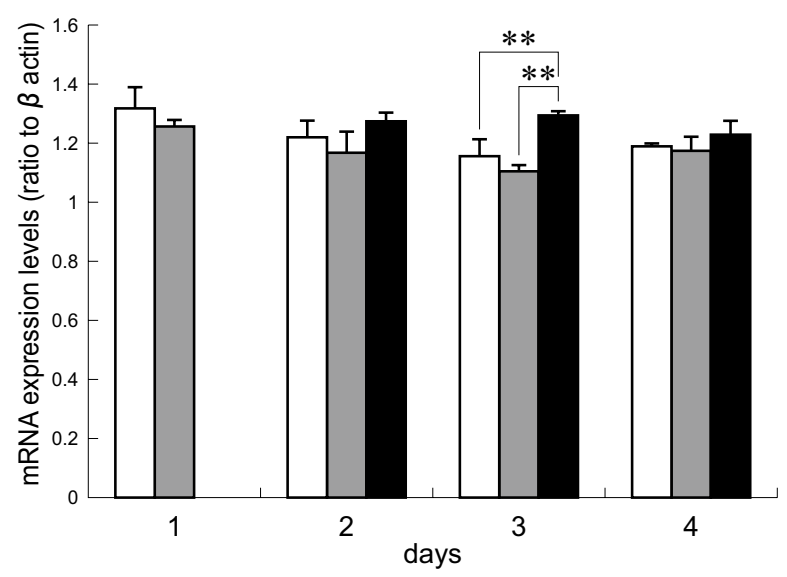

Fig. 4. mRNA expression levels of vascular endothelial growth factor (VEGF) in hypoxic conditions of rat dental pulp cells in culture. $\square$, Control; $\square$, hypoxia; reoxygenation. The expression of VEGF mRNA was significantly higher in the reoxygenation group than in the control and hypoxia groups on day $3(* * P<0.01)$. The expression of VEGF mRNA was significantly higher in the reoxygenation group than in the control and hypoxia groups on day $3(P<0.01)$. There was no significant difference in VEGF mRNA among the control, hypoxia and reoxygenation groups on days 1,2 and 4. 


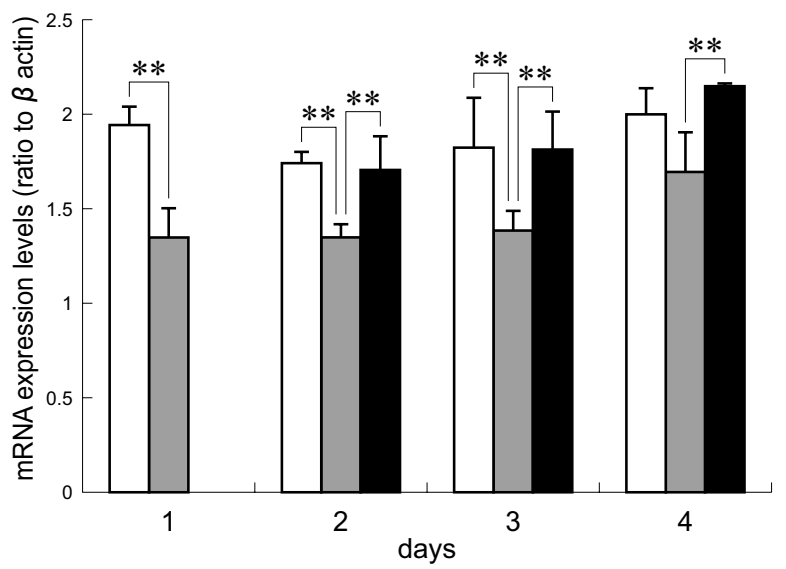

Fig. 5. mRNA expression levels of dentin sialophosphoprotein (DSPP) in hypoxic conditions of rat dental pulp cells in culture. $\square$, Control; $\square$, hypoxia; $\square$, reoxygenation. Expression of DSPP mRNA was significantly lower in the hypoxia group than in the control and the reoxygenation groups on days 2 and $3(* * P<0.01)$. Expression of DSPP mRNA was significantly lower in the hypoxia group than in the control group on days $1(* * P<0.01)$. Expression of DSPP mRNA was significantly higher in the reoxygenation group than in the hypoxia group $(* * P<0.01)$.

The expression of DSPP mRNA in the hypoxia group was significantly lower than in the control group on days 1 , 2 , and $3(P<0.01)$ (Fig. 5). It was significantly higher in the reoxygenation group than in the hypoxia group on days 2,3 and $4(P<0.01)$.

\section{Discussion}

Regarding the cell proliferation ratio of immature pulp cells, the hypoxia group showed a lower proliferation ratio than did the control group for each time period, except on day 1 in this study. Ueno et al. reported that short-term exposure to hypoxia (1\% oxygen tension for less then 24 hrs) did not affect the viability of the rat pulp cell line (RPCC2A-K4), while long-term exposure (over $24 \mathrm{hrs)} \mathrm{reduced}$ its viability. They concluded that the population of cells in the G1 phase increased but those in the S phase decreased after long-term exposure to hypoxia, which suggested that hypoxia suppresses the proliferation of pulp cells in a timedependent manner (10). Their findings support our results. Therefore, it appears that the proliferation activity of pulp cells from immature teeth also depends on oxygen concentration. On the other hand, the reoxygenation group also showed a lower proliferation ratio than the control group at days 2 and 3, although the ratio returned to the same level cycle to arrest the proliferation the G1 phase by inactivation of functioning molecules for DNA synthesis, which inhibits progression through the cell cycle $(10,14)$. This suggests that it takes more than $48 \mathrm{hrs}$ exposure of oxygen to increase cells at the S-phase and reestablish cell viability.

There are significantly higher levels of HIF- $1 \alpha$ under both hypoxic and reoxygenation conditions compared to the control group in this study. Nevertheless, no significant levels of VEGF were seen in either group at any of the time periods except for day 3. The expression of VEGF, which induces vascularization, is regulated by HIF- $1 \alpha$, which is known as a hypoxia-mediated regulator of gene transcription. It is known that HIF-1 $\alpha$ is up-regulated and is an inducer of angiogenesis under hypoxia (15). On the other hand, it has been also reported that the expression of VEGF mRNA (16) and pulpal blood flow (17) of young pulp tissue is higher than that of aging pulp tissue. The HIF- $1 \alpha$ expression patterns in our results suggest that the response of young rat pulp cells to hypoxic conditions might be independent of the expression of VEGF, since young pulp cells originally express high levels of VEGF and have high vascularization.

ALP has been associated with early osteogenesis or dentinogenesis (18), while DSPP is a tooth-specific gene produced by odontoblasts, and has been associated with odontoblast differentiation (19). Both are considered to be useful markers for early mineralization. In this study, the expression of DSPP mRNA in the hypoxia group was significantly lower than that of the control group although there was no significant difference in expression of ALP mRNA among all experimental groups at any of the time periods. Under hypoxic condition, the effects on osteoblastic differentiation in various osteogenic cells and the decrease of ALP in aged rat periodontal ligament cells $\mathrm{O}_{2}$ have been reported $(18,20)$. Our results with regard to ALP level suggested that young rat pulp cells had a higher capability for osteogenic potential than the aged rat cells. Shiba et al. (21) reported that ALP activity was increased in young donors and decreased with aging. Taken together, immature young pulp cells have high levels of ALP activity, and hypoxic conditions did not affect the expression of ALP.

Nohutcu et al. reported that the expression of DSPP in terminally differentiated odontoblasts is higher than in early differentiated odontoblasts (18). Muramatsu et al. reported that young pulp tissue has a high level of dentineogenic potential and differentiation ability compared with aged pulp (22). In the present study, there were significantly lower levels of DSPP at days 2 and 3 under hypoxic conditions compared with the control groups. It suggests that hypoxic conditions may decelerate odontoblast differentiation.

In conclusion, hypoxic conditions do not affect early dentinogenesis, but affect odontoblastic diffentiation. Furthermore, hypoxic conditions reduce cell proliferation in young pulp tissue. However, it was conceivable that reoxygenation within 24 hrs was able to reestablish cell proliferation and differentiation after the hypoxic condition.

\section{Acknowledgments}

We would like to thank Miss Saori Takano and members of the Department of Clinical Pathophysiology for their technical assistance. This research was in part supported by an Oral Health Science Center Grant HRC7 from the Tokyo Dental College and by a "High-Tech Research Center" Project for Private Universities: Matching Fund Subsidy from MEXT (Ministry of Education, Culture, Sports, Science and Technology) of Japan, 2006-2010, and 2007-2010 (No. 19592414). 


\section{References}

1. He T, Deng Y. Microvasculature of the dog's periodontal ligament and its immediate response to orthodontic forces. Hua Xi Kou Qiang Yi Xue Za Ahi 1998; 16: 29-31.

2. Kim S, Edwall L, Trowbridge H, Chien S. Effects of local anesthetics on pulpal blood flow in dogs. J Dent Res 1984; 63: $650-2$.

3. Gazelius B, Olgart L, Edwall B, Edwall L. Non-invasive recording of blood flow in human dental pulp. Endod Dent Traumatol 1986; 2: 219-21.

4. Pfeifer S, Hillertk A, Gotzfried M, Schmalz G. Periodontal disease and smoking. DE J Dent Eng 2006; 158: 13-6.

5. Astrup J, Symon L, Branston NM, Lassen NA. Cortical evoked potential and extracellular $\mathrm{K}^{+}$and $\mathrm{H}^{+}$at critical levels of brain ischemia. Stroke 1977; 8: 51-7.

6. Lowly OH, Passonneau JV, Hasselberger FX, Schultz DW. Effects of ischemia on known substrates and cofactors of glycolytic pathway in brain. J Biol Chem 1964; 239: 18-30.

7. Kikuchi K, Hayashi J, Jinzenji S. Stimulated production of bone-resorbing factors by reoxygenation after hypoxia in cultured human periodontal ligament cells. J Meikai Dent Med 2006; 35: 35-41.

8. Amemiya H, Matsuzaka K, Kokubu E, Ohta S, Inoue T. Cellular responses of rat periodontal ligament cells under hypoxia and re-oxygenation conditions in vitro. J Periodont Res 2008; 43: 322-7.

9. Amemiya K, Kaneko Y, Muramatsu T, Shimono M, Inoue T. Pulp cell responses during hypoxia and reoxygenation in vitro. Eur J Oral Sci 2003; 111: 332-8.

10. Ueno Y, Kitamura C, Terashita M, Nishihara T. Reoxygenation improves hypoxia-induced pulp Cell arrest. $J$ Dent Res 2006; 85: 824-8.

11. Fukuyama Y, Ohta K, Okoshi R, Suehara M, Kizaki H, Nakagawa K. Hypoxia induces AMPK in dental pulp cells. J Dent Res 2007; 86: 903-7.

12. Ferrara N. The role of vascular endothelial growth factor in pathological angiogenesis. Breast Cancer Res Treat 1995; 36: 127-37.
13. Zhang W, Walboomers F, Shi S, Fan Mingwen, Jansen AJ. Multilineage differentiation potential of stem cells derived from human dental pulp after cryopreservation. Tissue Eng 2006; 12: 2813-23.

14. Gardner LB, Li Q, Park MS, Flangan WM, Semenza GL, Dang CV. Hypoxia inhibits G1/S transition through regulation of p27 expression. J Biol Chem 2001; 276: 7919-26.

15. Wang GL, Jisng BH, Rue EA, Semenza GL. Hypoxiainducible factor-1 is a basic helix-loop-PAS heterodimer regulated by cellular $\mathrm{O}_{2}$ tension. Proc Natl Acad Sci USA 1995; 92: 5510-4.

16. Wang Q, Lin XJ, Lin ZY, Lin GX, Shan XL. Expression of vascular endothelial growth factor in dental pulp of immature and mature permanent teeth in human. Shanghai Kou Qiang Yi Xue 2007; 16: 285-9.

17. Shinoguchi K, Shirakawa T, Miura M, Oguchi H. Laser Doppler flowmetry for non-invasive measurement of pulpal blood flow in immature permanent teeth. Jpn J Ped Dent 1991; 29: 688-97. (in Japanese)

18. Nohutcu RM, McCauley LK, Koh AJ, Somerman MJ. Expression of extracellular matrix proteins in human periodontal ligament cells during mineralization in vitro. $J$ Periodontol 1997; 68: 320-7.

19. Narayanan K, Ramachandran A, Peterson MC, et al. The CCAAT enhancer-binding protein (C/EBT) $\beta$ and Nrf1 interact to regulate dentin sialophosphoprotein (DSPP) gene expression during odontoblast differentiation. J Biol Chem 2004; 279: 42423-5432.

20. Chen SH, Inoue T, Shimono M. An experimental study of osteogenesis in explants of rat dental pulp, periodontal ligament, bone marrow and muscle cells in vitro. Bull Tokyo Dent Coll 1989; 30: 155-64.

21. Shiba H, Nakanishi K, Rahmide F, et al. Proliferative ability and alkaline phosphatase activity with in vivo cellular aging human pulp cells. J Endod 2003; 29: 9-11.

22. Muramatsu T, Hamano H, Ogami K, Ohta K, Inoue T, Shimono M. Reduction of connexin 43 expression in aged human dental pulp. Int Endod J 2004; 37: 814-8. 